\title{
TANTANGAN DALAM MENINGKATKAN KEMAMPUAN BERBICARA MAHASISWA DENGAN METODE PEMELAJARAN WAWANCARA
}

\author{
Wuri Syaputri ${ }^{1}$, Lina Septianasari ${ }^{2}$, Fourus Huznatul Abqoriyyah $^{3}$ \\ ${ }^{1}$ Universitas Indonesia, ${ }^{2}$ STKIP Muhammadiyah Bogor, ${ }^{3}$ Universitas Al-Ghifari \\ 1wurisyaputri@gmail.com
}

\begin{abstract}
This study answers the problem of the effectiveness of the interview learning method in students' speaking classes. In addition, this study also looked at the challenges of lecturers in speaking learning. The practice of language in the class is observed and given an experiment is the Speaking class at the beginner level at Muhammadiyah University of Pringsewu. The number of students who were the research subjects is 72 students. All students will get treatment according to their research needs. The results of t-test statistical calculations shown, where the t-test is 4.66 higher than the t-table is 2.06 , it means that the Ha hypothesis in this study is accepted. Based on observations notes, the interview method also hasn't worked perfectly to get students to be active in class. This is a concern because there are still 5 students who choose to remain silent when invited to speak by the lecturer.
\end{abstract}

Keywords: Challange, Speaking, Interview

\section{ABSTRAK}

Penelitian ini menjawab permasalahan tentang kefektifan metode pemelajaran wawancara di kelas berbicara mahasiswa. Selain itu, penelitian ini juga melihat tantangan dosen dalam pemelajaran berbicara. Praktik bahasa dalam kelas diamati dan diberi eksperimen adalah kelas Speaking pada level beginner di Universitas Muhammadiyah Pringsewu. Mahasiswa yang menjadi subjek penelitian berjumlah 72 mahasiswa. Seluruh mahasiswa akan mendapatkan perlakuan sesuai dengan kebutuhan penelitian. Hasil penghitungan statistik $t$-test menunjukkan, dimana $t$ test 4,66 lebih tinggi dari t-table adalah 2,06 itu berarti hipotesis Ha dalam penelitian ini diterima. Berdasarkan catatan hasil pengamatan, metode wawancara juga belum berhasil sempurna untuk mengajak mahasiswa menjadi aktif di kelas. Hal ini menjadi perhatian karena masih muncul 5 mahasiswa yang memilih diam ketika diajak berbicara oleh dosen.

Kata Kunci: Tantangan, Berbicara, Wawancara

Submitted Mar 28, 2020 | Revised May 03, 2020 | Accepted May 04, 2020

\section{Pendahuluan}

Bahasa menjadi penting sebagai alat komunikasi antarbangsa (Rondiyah, Wardani, and Saddhono 2017). Bahasa juga memudahkan dalam berkomunikasi baik komunikasi secaralisan maupun tulis, terutama untuk dalam proses pemelajaran dan menyelesaikan tugas akademik di kampus (Saddhono 2012). Basically, learning language helps students to develop their self-awareness and cultures. Furthermore, language encourages students to express their opinions and feeling, to participate in social interaction, and to use their analytic and imaginative ability (Saddhono and Rohmadi 2014).Bahasa juga dapat menjadi sarana manusia dalam menyampaikan pemikiran atau penalaran, sikap dan perasaannya. Manusia berinteraksi dan berkomunikasi, mencari informasi dengan 
menggunakan bahasa. Secara khusus, kemampuan menggunakan bahasa, tidak dibawa sejak lahir dan tidak dapat dikuasai dengan sendirinya melainkan harus dipelajari (Ningsih 2014).

Keterampilan berbahasa, yaitu berbicara adalah kegiatan menyampaikan ide, gagasan, pikiran, dan perasaan dengan tujuan tertentu yang diungkapkan dengan ujaran kepada pendengar atau lawan tutur. Berbicara merupakan keterampilan penting yang harus diperoleh seorang pemelajar bahasa. Hal ini betujuan agar dapat berkomunikasi secara efektif melalui bahasa lisan dan dapat membuat pemelajar dapat mengekspresikan ide-ide bahkan dalam bentuk percakapan yang sederhana. Seperti halnya yang terjadi di Perguruan Tinggi, mahasiswa dituntut untuk kritis dalam berkomunikasi terlebih komunikasi lisan (Darmuki et al. 2015). Sedangkan menurut Tarigan (1983) mengemukakan bahwa berbicara adalah kemampuan mengucapkan bunyi-bunyi artikulasi atau kata-kata untuk mengekspresikan, menyatakan serta menyampaikan pikiran, gagasan, dan perasaan. Berbicara merupakan suatu sistem tanda-tanda yang dapat didengar (audible) dan yang kelihatan (visible) yang memanfaatkan sejumlah otot dan jaringan otot manusia demi maksud dan tujuan gagasan-gagasan yang dikombinasikan (Saddhono and Slamet 2014). Belajar bahasa berarti siap melaksanakan praktik bahasa baik secara lisan dan tulisan.

Menurut Nurdin (2016) berbicara adalah kinerja untuk mengucapkan suara atau katakata artikulasi untuk mengekspresikan, mengekspresikan dan menyampaikan pikiran, ide, dan perasaan. Keterkaitan antara pesan dan penutur sebagai media adalah pesan yang diterima dengan baik oleh lawan tutur tidak dalam bentuk aslinya, tetapi dalam bentuk lain yaitu bahasa yang diucapkan. Keraf (1977) membedakan jenis berbicara ke dalam tiga macam yaitu persuasif, instruktif, dan rekreatif. Termasuk jenis persuasive adalah mendorong, meyakinkan, dan bertindak. Berbicara instruktif bertujuan untuk memberitahukan. Berbicara rekreatif bertujuan untuk menyenangkan. Jenis-jenis berbicara tersebut menghendaki reaksi dari para pendengar yang beraneka. Berbicara persuasif, menghendaki reaksi dari para pendenngar untuk mendapatkan ilham/inspirasi. Atau membangkitkan emosi; untuk mendapatkan persesuain pendapat, intelektual, dan keyakinan; dan mendapatkan tindakan/perbuatan tertentu dari pendengar. Berbicara instruktif menghendaki reaksi dari pendengar berupa pengertian yang tepat. Sedang berbicara rekreatif menghendaki reaksi dari pendengar berupa minat dan kegembiraan (Saddhono and Slamet 2014).

Berdasarkan penjelasan di atas,dapat disimpulkan bahwa mahasiswa memerlukan cara interaktif untuk berlatih bahasa. Menurut Anas dan PdI (2014) ada cara yang lebih 'menghidupkan' suasana pemelajaran yaitu metode pemelajaran wawancara. Para mahasiswa membutuhkan lebih banyak kegiatan melalui teman sebaya atau dosen. Para mahasiswa membutuhkan motivasi secara langsung. Melalui metode pemelajaran wawancara, diharapkan menjadi cara yang efektif untuk mengajar kelas berbicara dibandingkan dengan metode ceramah. Metode wawancara digunakan untuk melihat bagaimana kefektifan kelas berbicara dan apa daja yang akan menjadi tantangan dosen di dalam kelas. Tantangan dalam mengajar akan menjadi motivasi bagi dosen untuk lebih kreatif di dalam kelas (Septianasari 2019). Dosen akan lebih kreatif karena munculnya permasalahan-permasalahn yang mungkin saja terjadi di dalam kelas (Syaputri 2019). Praktik bahasa dalam kelas yang akan diamati dan diberi eksperimen adalah kelas Speaking pada level beginner di Universitas Muhammadiyah Pringsewu. Mahasiswa yang akan menjadi subjek penelitian berjumlah 72 mahasiswa. Seluruh mahasiswa akan mendapatkan perlakuan sesuai dengan kebutuhan penelitian. 


\section{Metode Penelitian}

Dalam penelitian ini, desain penelitian menggunakan desain eksperimental. Penelitian ini menggunakan pre test dan post test. Menurut Bosworth dan Hamilton (1994)kelompok eksperimen biasanya menerima penafsiran baru, analisis, sedangkan kelompok kontrol biasanya menerima perlakuan berbeda atau diperlakukan seperti biasa. Sehingga peneliti menggunakan dua kelas, yaitu: kelas eksperimen dan kelas kontrol untuk mengetahui metode pemelajaran yang lebih efektif untuk pengajaran berbicara. Jumlah mahasiswa masing-masing kelas berjumlah 36 mahasiswa. Total mahasiswa yang dijadikan sampel penelitian adalah 72 mahasiswa.

Pada praktik penelitian, mahasiswa diberi instruksi bagaimana instruksi kelas berbicara ke kelas eksperimen dengan metode wawancara, sedangkan pada kelas kontrol tetap seperti biasa menggunakan metode ceramah. Berikut ini daftar materi yang diberikan pada kelas eksperimen dan kelas kontrol.

Tabel 1.

Materi Kelas Eksperimen dan Kelas Kontrol

\begin{tabular}{cl}
\hline Pertemuan ke- & Materi \\
\hline $\mathbf{1}$ & Melafalkan 20 bunyi vokal (vocal phonemes) \\
$\mathbf{2}$ & Menjodohkan kata-kata tertentu sesuai dengan bunyi yang sesuai \\
$\mathbf{3}$ & Mengucapkan tegur sapa dengan benar \\
4 & Mengucapkan kata perpisahan dengan benar \\
\hline
\end{tabular}

Mahasiswa diberi tes berupa tes awal dan tes akhir. Tes awal berisikan keempat materi diatas berupa 20 butir soal. Pada praktik penelitian, mahasiswa di panggil satu persatu di dalam kelas, sedangkan mahasiswa lainnya yang sedang menunggu giliran diminta untuk mempelajari materi yang akan dibahas ketika bertemu dosen. Secara teknis, pertama siswa akan mengenalkan diri dengan menyebutkan nama dan NPM. Langkah kedua, mahasiswa akan diajak berbicara dengan percakapan bergilir antara dosen dengan mahasiswa. Sebagai contoh pada materi pertama. Sebagai awal pembicaraan mahasiswa akan ditanya beberapa kosa kata, kemudian cara membacanya. Pada tahapan ini, dosen memberikan konfirmasi apakah mahasiswa sudah benar atau belum dalam pengucapan kosa kata yang menjadi topik bahasan pada masing-masing pertemuan. Pada sesi ini pun mahasiswa disilakan untuk membawa kamus, telepon genggam dan laptop sebagai alat bantu. Keadaan kelas dan suasana dibuat santai dengan tujuan agar siswa tidak takut dan gugup. Langkah ketiga, mahasiswa disilakan untuk memberikan salam penutup sebagai tanda sesi wawancaranya telah usai.

Penelitian ini menggunakan metode eksperimen, dengan menganalisis data. Peneliti menggunakan statistik inferensial. Statistik infensial digunakan untuk menjawab pertanyaan apakah ada efektivitas metode wawancara terhadap kemampuan berbicara mahasiswa. Untuk menjawab permasalahan mengenai bagaimana kefektifan metode tersebut, penelitian ini menerapkan tiga tes menurut Sugiyono (2015), yaitu uji normalitas, uji homogenitas dan Uji hipotesis. Selain itu, untuk menjawab permasalahan mengenai tantangan dosen dalam pengajaran berbicara menggunakan metode wawancara dilakukan pengamatan secara 
mendalam terhadap mahasiswa selama proses belajar mengajar di kelas berbicara. Informasi tambahan juga didapatkan dengan metode catat agar memudahkan dalam tahap analisis. Catatan di lapangan akan menjadi data pendukung pada penelitian ini.

\section{Hasil dan Pembahasan}

Peneliti melakukan uji coba untuk mendapatkan uji validitas dan reliabilitas. Jika tes telah valid dan dapat diandalkan, tes dapat digunakan sebagai studi. Kemudian, peneliti menggunakan pretest dan post test sebagai instrumen. Sebelum melakukan tes, instrumen seharusnya sudah diketahui valid. Pengukuran tes berbicara menggunakan validitas konten melalui uji coba. Peneliti memberikan uji coba sekali untuk 15 siswa. Setelah menghitung, tes ini dapat diandalkan; itu berarti instrumen tersebut valid. Jadi, peneliti menggunakan uji coba untuk diuji. Peneliti menggunakan pertanyaan yang sama untuk pretest dan posttest. Keandalan tes diperlukan agar tes tersebut dipercaya. Peneliti menggunakan rumus product moment untuk mengetahui reliabilitas tes. Keduanya dikorelasikan dengan menggunakan rumus Spearman-Brown.

Setelah dihitung dengan menggunakan rumus product moment, didapatkan 0,99 dalam uji coba yang artinya validitas instrumen tes berbicara termasuk kategori tinggi. Perhitungan bahwa dengan menggunakan rumus Spearman-brown, ri pertama diperoleh $=0,99$. Jika hasilnya berkonsultasi dengan $\mathrm{r}$ skor, itu berarti bahwa hasilnya memiliki interpretasi yang tinggi. Jadi, tes itu dapat diandalkan dan dapat digunakan untuk penelitian.

Tabel 2.

Nilai Pre Test Berbicara

\begin{tabular}{cccc}
\hline Kelompok & Nilai Tertinggi & Nilai Terendah & Rata-rata \\
\hline A1 & 70 & 41 & 56,5 \\
A2 & 69 & 41 & 54,5 \\
\hline
\end{tabular}

Hasil penelitian menunjukkan bahwa skor rata-rata kemampuan berbicara di kelas sekitar 64\%. Ini berarti bahwa kemampuan berbicara rendah. Hal ini didukung oleh skor pretest eksperimen dan kelas kontrol rendah. Pre-test diberikan kepada 72 siswa. Di kelas eksperimen skor tertinggi adalah 70 dan terendah 41 yang memiliki rata-rata 56,5. Sementara itu, di kelas kontrol skor tertinggi adalah 69 dan skor terendah adalah 41 yang memiliki ratarata 54,5 .

Berdasarkan data pre-test, kelas eksperimen lebih tinggi dari kelas kontrol. Dalam penelitian ini, peneliti telah melakukan empat kali perlakuan dalam empat kali pertemuan. Dan setiap perlakuan terdiri dari empat topik. Di kelas eksperimen, untuk perlakuan pertama, skor tertinggi adalah 65, dan skor terendah adalah 55. Di perlakuan kedua, skor tertinggi adalah 70, dan skor terendah , skor tertinggi adalah 71, dan skor terendah adalah 65. Perlakuan keempat, skor tertinggi adalah 80 , dan skor terendah adalah 70 . Skor total perlakuan pertama hingga dua perlakuan di kelas eksperimen adalah 92,37. Post test diberikan setelah peneliti melakukan 
empat tahap. Post test diberikan kepada kedua kelas untuk mengetahui kinerja berbicara siswa setelah mereka menerima perlakuan. Post test diadakan secara bersamaan 2x45 menit.

Tabel 3.

Uji Homogenitas

\begin{tabular}{cccc}
\hline Kelompok & $\mathrm{X}^{2} \mathrm{r}$ & $\mathrm{X}^{2} \mathrm{t}$ & Keterangan \\
\hline A1 dan A2 Pre Test & 5,42 & 8,38 & Homogen \\
A1 dan A2 Post Test & 4,57 & & \\
\hline
\end{tabular}

Hasil uji distribusi normalitas dan homogenitas adalah 4,57 (Pre-test) dan 5,42 (Post test) untuk kelas eksperimen. Uji normalitas dilakukan untuk mengetahui apakah data kedua kelas berdistribusi normal atau tidak. Data seharusnya normal jika L-rasio lebih rendah dari Ltabel pada tingkat signifikansi 0,05 . Data seharusnya normal jika L-tabel lebih tinggi dari Lrasio pada tingkat signifikan 0,05.Berdasarkan distribusi frekuensi data pre-test, diperoleh bahwa dari 36 siswa di kelas eksperimen, antaranya 5 siswa mendapatkan skor antara 41-45, 7 siswa mendapatkan nillai antara 46-50, 7 siswa mendapatkan nilai antara 51-55, 9 siswa mendapatkan nilai antara 56-60, 6 siswa antara 61-65 dan 2 siswa mendapatkan nilai antara 6670. Untuk kelas eksperimen post test data, berdasarkan distribusi frekuensi, terdapat 3 siswa mendapat skor antara 61-65, 6 siswa antara 66-70, 10 siswa antara 71-75, 15 siswa antara 7680, 2 siswa antara 81- 85 dan 2 siswa berusia antara 86-90. Untuk kelas kontrol memiliki nilai 5.77 (Pre-test) dan 8.38 (Post test). Nilai-nilai ini terkecil dari tabel chi-kuadrat dengan $\alpha 5 \%$ $(4,57)$ dan $\alpha 1 \%(5,42)$.

Berdasarkan distribusi frekuensi data pre-test, diperoleh bahwa dari 36 siswa di kelas kontrol ada 5 siswa mendapat skor antara 40-44, 6 siswa mendapat 45-49, 10 siswa mendapat 50-54, 9 siswa mendapat 55 - 59, 4 siswa mendapat 60 - 64 dan 2 siswa mendapatkan 65-69. Data post test di kelas kontrol, b erdasarkan distribusi frekuensi, ada 5 siswa mendapat skor antara 60-62, 3 siswa antara 63-65, 10 siswa antara 66-68, 14 siswa antara 69-71, 3 siswa antara 72-74, dan 2 siswa antara 75-77.

Sebelum menganalisis siswa menggunakan t-test, perlu untuk mengetahui apakah data pada kedua kelompok itu homogen. Untuk melakukan ini peneliti menggunakan F-test, data dikatakan homogen jika F-tabel lebih tinggi dari F-rasio. Kriteria untuk uji homogenitas adalah:

Ho; varians datanya homogen.

Ha: Varians data tidak homogen.

Berikut ini akan disajikan tabel hasil uji normalitas:

Tabel 4.

Uji Normalitas

\begin{tabular}{llll}
\hline Kelompok & $\mathrm{F}_{\text {rasio }}$ & $\mathrm{F}_{\text {tabel }}$ & Keterangan \\
\hline Pre Test & 1,15 & 2,67 & Normal \\
Post Test & 0,43 & 2,67 & Normal \\
\hline
\end{tabular}


Selanjutnya, data memiliki distribusi homogenitas dengan nilai 1,15 pada pre-test dan 0,43 pada post test. Nilai-nilai ini lebih kecil dari $F_{\text {tabel }} \alpha 5 \%(1,98)$ dan $1 \%(1,98)$. Setelah mengetahui data normal dan homogenitas, maka dapat dicari hipotesisnya. Hasil hipotesis adalah 4,66 dengan signifikan $\alpha 5 \%(2,66)$ dan $\alpha 1 \%(2,00)$.

Tabel 5.

\begin{tabular}{|c|c|c|c|}
\hline \multicolumn{4}{|c|}{ Uji t } \\
\hline Kelompok & $\mathrm{t}_{\text {rasio }}$ & $\mathrm{t}_{\text {tabel }}$ & Keterangan \\
\hline $\begin{array}{ll}A_{1} & \text { dengan } \\
A_{2} & \end{array}$ & 4,66 & 2,06 & Signifikan \\
\hline
\end{tabular}

Keterangan:

A1 : Kelompok Eksperimen

A2 : Kelompok Kontrol

Peneliti melakukan uji-t untuk membuktikan hipotesis yang diajukan terhadap hasil post test. Kriteria untuk uji hipotesis ini adalah menerima Ha jika t-rasio lebih tinggi dari ttabel pada tingkat signifikansi tertentu, dalam hal ini peneliti menggunakan 0,05. Berdasarkan data penghitungan uji t, terlihat bahwa t-rasio lebih tinggi dari t-tabel. Pada tingkat signifikansi 0,05 adalah 2,06. Berdasarkan kriteria di atas, Ho ditolak dan Ha diterima. Ini berarti bahwa, ada hasil yang signifikan dari kemampuan berbicara siswa dalam pengajaran menggunakan metode wawancara. Selain itu, terdapat juga data lapangan pada saat proses belajar mengajar di kelas berbicara mahasiswa dengan menggunakan metode wawancara baik di kelas eksperimen maupun di kelas kontrol.

Kelas eksperimen (metode pemelajaran wawancara)

Data 1. 15 Oktober 2019: 5 mahasiswa terlihat malu dan memilih diam ketika diajak berbicara secara langsung.

Data 2. 15 Oktober 2019: 3 mahasiswa terlihat gugup.

Kelas kontrol (metode pemelajaran ceramah)

Data 3. 16 Oktober 2019: 36 mahasiswa diam di kelas.

Data catatan di atas merupakan hasil pengamatan lapangan ketika melakukan eksperimen metode wawancara pada kelas berbicara. Pada data tersebut, ada dua permasalahan yang dihadapi dosen dalam mengajar menggunakan metode wawancara dan hanya satu permasalahan yang ditemui pada kelas kontrol. Namun, dua permasalahan yang muncul apda kelas eksperimen justru memberrikan gambaran bahwa metode pemelajaran wawancara lebih efektif dibandingkan dengan metode ceramah untuk kelas berbicara. Pada data 1 disebutkan bahwa ada 5 mahasiswa yang terlihat malu dan diam, sedangkan pada kelas kontrol, data 3 ada 36 mahasiswa yang diam. Hal ini menunjukkan bahwa mahasiswa kurang mendapatkan perlakuan jika kelas berbicara dengan menggunakan metode ceramah.

\section{Kesimpulan}

Penelitian ini menunjukkan bahwa ada peningkatan skor berbicara kelompok eksperimen menggunakan metode wawancara. Penelitian ini berkaitan dengan penggunaan 
metode wawancara sebagai teknik yang dipilih untyk diterapkan pada kelompok eksperimen. Karena nilai tes berbicara siswa meningkat secara signifikan, dapat disimpulkan bahwa kemampuan mereka dalam berbicara, terutama dalam pengucapan, kelancaran, pemahaman kosa kata dalam metode wawancara efektif. Berdasarkan hasil analisis dan perhitungan data, peneliti menyimpulkan bahwa signifikansi penggunaan metode wawancara terhadap kemampuan berbicara di kelas berbicara mahasiswa efektif. Berdasarkan hasil statistik t-test, dimana t-test 4,66 lebih tinggi dari t-tabel adalah 2,06 itu berarti hipotesis Ha dalam penelitian ini diterima.

Metode wawancara dapat membuat siswa menjadi aktif dalam belajar dengan dibuktikan adanya perbedaan jumlah mahasiswa yang diam dikelas eksperimen sejumlah 5 orang dan seluruh mahasiswa di kelas kontrol.. Dalam metode wawancara siswa dituntut untuk melakukan lebih banyak praktik berbicara dibandingkan dengan metode pemelajaran ceramah. Sehingga siswa akan mengerti tentang apa yang harus dikatakan ketika praktik di kelas. Berdasarkan statistik, hasil uji-t, dimana t-hitung 4,66 lebih tinggi dari t-tabel adalah 2,06 dan juga dari hasil skor rata-rata siswa di kelas eksperimen adalah 56,5 pada pre-test dan 73,8 pada post test. Ini berarti bahwa ada hasil yang signifikan dari metode wawancara terhadap kemampuan berbicara. Sealian itu, berdasarkan catatan hasil pengamatan, metode wawancara juga belum berhasil sempurna untuk mengajak mahasiswa menjadi aktif di kelas. Hal ini menjadi perhatian karena masih muncul 5 mahasiswa yang memilih diam ketika diajak berbicara oleh dosen.

\section{Daftar Pustaka}

Anas, Muhammad, and M. PdI. (2014). Mengenal Metodologi Pemelajaran. Muhammad Anas.

Bosworth, Kris, and Sharon J. Hamilton. (1994). Collaborative Learning: Underlying Processes and Effective Techniques: New Directions for Teaching and Learning, Number 59. Vol. 73. JosseyBass.

Darmuki, Agus, Andayani Andayani, Joko Nurkamto, and Kundharu Saddhono. (2015). "Model Student Learning To Speak For Education Study Language And Literature Indonesia: Document Analysis And Needs Learning To Speak." Prosiding Prasasti 99_ 109.

Keraf, Gorys. (1977). “Komposisi: Sebuah Pengantar Kepada Kemahiran Bahasa.” Ende-Flores: Nusa Indah.

Ningsih, Suwarti. (2014). "Peningkatan Keterampilan Berbicara Melalui Metode Bercerita Siswa Kelas III SD Negeri 1 Beringin Jaya Kecamatan Bumi Raya Kabupaten Morowali." Jurnal Kreatif Online 2(4).

Nurdin. (2016). "Penerapan Kemampuan Berbicara Dengan Metode Cooperativ Learning Tipe Artikulasi Pada Siswa Kelas X MAN 1 Mataram." Jurnal Ilmiah Mandala Education 2(2):35-52.

Rondiyah, Arifa Ainun, Nugraheni Eko Wardani, and Kundharu Saddhono. (2017). "Pemelajaran Sastra Melalui Bahasa Dan Budaya Untuk Meningkatkan Pendidikan Karakter Kebangsaan Di Era Mea (Masayarakat Ekonomi Asean).” in Proceedings Education and Language International Conference. Vol. 1. 
Saddhono, Kundharu. (2012). "Kajian Sosiolinguistik Pemakaian Bahasa Mahasiswa Asing Dalam Pemelajaran Bahsa Indonesia Untuk Penutur Asing (BIPA) Di Universitas Sebelas Maret.” Kajian Linguistik Dan Sastra 24(2):176-86.

Saddhono, Kundharu, and Muhammad Rohmadi. (2014). "A Sociolinguistics Study on the Use of the Javanese Language in the Learning Process in Primary Schools in Surakarta, Central Java, Indonesia." International Education Studies 7(6):25-30.

Saddhono, Kundharu, and Y. Slamet. (2014). Pemelajaran Keterampilan Berbahasa Indonesia: Teori Dan Aplikasi. Graha Ilmu.

Septianasari, Lina. (2019). "Mother Tongue Issues And Challenge In Learning English As Foreign Language." International Journal of Indonesian Education and Teaching (IJIET) 3(2):204-214.

Sugiyono, Metode. (2015). "Penelitian \& Pengembangan (Research and Development/R\&D)." Bandung: Penerbit Alfabeta.

Syaputri, Wuri. (2019). "First Language Morphological Interference of English Language Learners (EFL)." in Seventh International Conference on Languages and Arts (ICLA 2018). Atlantis Press.

Tarigan, Djago. (1983). Materi Pokok Pendidikan Bahasa Indonesia I Universitas Terbuka. Jakarta: Depdikbud. 